\title{
PERCEPÇÃO AMBIENTAL DE PROPRIETÁRIOS RURAIS DO MUNICÍPIO DE CASTILHO
}

\author{
Aparecida Brunetti Arante de Souza ${ }^{1}$ \\ Sérgio Luís de Carvalho ${ }^{2}$ \\ Elizete Aparecida Checon Freitas Lima ${ }^{3}$
}

\begin{abstract}
RESUMO
A gestão racional de recursos está ligada intimamente à maneira como proprietários rurais compreendem cada um dos bens que os cercam e os servem, dado o fato de que a compreensão influencia o comportamento humano para com o ambiente natural. O objetivo do presente trabalho foi caracterizar a percepção ambiental de produtores rurais do município de Castilho-SP e avaliar a importância atribuída por eles aos recursos naturais existentes nos locais de investigação. Entrevistas in loco por meio de questionário puderam evidenciar necessidades específicas no âmbito da Educação ambiental quanto aos conhecimentos sistematizados de conservação de recursos naturais. Dentre os diversos aspectos enfatizados no questionário, destacou-se a percepção ambiental como processo avaliativo do conhecimento e comportamento dos produtores rurais em relação ao manejo dos recursos naturais dos quais dispõem. O trabalho revelou que de forma generalizada os produtores rurais demonstram conhecimento acerca da importância da conservação ambiental, predominando o senso comum, entretanto o tema é tratado de forma vaga ou ainda sem interesse. Com tais informações entende-se a necessidade de investimentos em educação ambiental voltados ao público da zona rural, fortalecendo e melhorando sua relação com o meio.
\end{abstract}

PALAVRAS-CHAVE: Conservação ambiental. Recursos naturais. Preservação.

\section{ENVIRONMENTAL AWARENESS OF FARMERS FROM CASTILHO CITY}

\begin{abstract}
The racional management of resources is closely associated to the way that farmers realize each asset among them and how it can be used, wherein the comprehension can cause some influence in human behavior for the natural environment. The goal of this essay was give characteristics to farmers' environmental perception, from Castilho, SP, and evaluate the importance given by them to natural resources on the investigation places. Interviews in loco by a quiz could give evidences to the specifics needing into environmental education about systematized knowledge of natural resources

\footnotetext{
${ }^{1}$ Graduanda em Ciências Biológicas na Universidade de Engenharia de llha Solteira (UNESP). Email: aparecidabrunetti@yahoo.com.br

${ }^{2}$ Doutor em Ecologia pela Universidade de Campinas/UNICAMP, Brasil. Professor Adjunto na

Faculdade de Engenharia de llha Solteira (UNESP). E-mail: sergicar@bio.feis.unesp.br.

${ }^{3}$ Doutora em Ecologia pela Universidade Federal de São Carlos/UFSCAR, Brasil. Professora Doutora na Faculdade de Engenharia de Ilha Solteira (UNESP). E-mail: eacfl@bio.feis.unesp.br.
} 
conservation. Among the various aspects treated at the quiz, stood out the environmental awareness as an evaluating process of farmers' knowledge and behavior based to the natural resources management in that are available. The work revealed that, in a general way, the farmers showed knowledge about the importance of environment conservation, predominating the common sense, however the theme is treated without some interest. With these informations, can be understood the necessity of investments in environmental education focused in people from countryside, becoming better their interation with this idea.

KEYWORDS: Environmental conservation. Natural resources. Preservation.

\section{PERCEPCIÓN AMBIENTAL DE PROPIETARIOS RURALES DEL MUNICIPIO DE CASTILHO}

\section{RESUMEN}

La gestión racional de recursos está íntimamente ligada a la manera en que los propietarios rurales entienden cada uno de los bienes que les rodean y les sirven, ya que la comprensión influye en el comportamiento humano para con el medio natural. El objetivo del presente trabajo fue caracterizar la percepción ambiental de productores rurales del municipio de Castilho en el Estado de São Paulo, y evaluar la importancia atribuida por éstos a los recursos naturales existentes en los lugares de investigación. Entrevistas in situ mediante cuestionario evidenciaron necesidades específicas en el ámbito de la Educación ambiental, en lo que se refiere a los conocimientos sistematizados de conservación de recursos naturales. Entre los diversos aspectos enfatizados en el cuestionario, se destacó la percepción ambiental como elemento de evaluación del conocimiento y comportamiento de los productores rurales en relación al manejo de los recursos naturales de los que disponen. El trabajo reveló que, de forma generalizada, los productores rurales demuestran conocimiento acerca de la importancia de la conservación ambiental, predominando el sentido común. Sin embargo, el tema es tratado de forma vaga o directamente sin interés. En base a esta información, se evidencia la necesidad de invertir en Educación ambiental dirigida al público de la zona rural, fortaleciendo y mejorando su relación con el medio.

PALABRAS CLAVE: Conservación ambiental. Recursos naturales. Preservación.

\section{INTRODUÇÃO}

O produtor rural como agente modificador da área onde habita é responsável pela alteração do espaço e causador de transformações ecossistêmicas. Quaisquer que sejam os meios técnicos utilizados e seus graus de tecnologia para o manejo do solo e criação de culturas e animais, a transformação ambiental é iminente a cada ação realizada para viabilizar a sobrevivência neste meio.

As modificações mais esperadas são especialmente referentes à qualidade $\mathrm{e}$ condições do solo, água, clima e consequentemente, produtividade agrícola e animal. Logo, tais condições solicitam a existência de uma gestão consciente de que os recursos são bens que podem ser usufruídos, contudo conservados e ainda há aqueles que devem ser mantidos intactos, preferencialmente. 
A gestão racional dos recursos está ligada intimamente à maneira como os proprietários compreendem cada um dos bens que os cercam e os servem, portanto, a compreensão influencia o comportamento humano para com o ambiente natural.

A percepção é uma técnica que exige desenvolvimento e exercício. Poucas
pessoas conseguem compreender todo o escopo dos seus ambientes
diários. Pode haver uma ideia vaga de que o espaço e os objetos têm
qualidades estéticas ou vivificantes, mas a relação será normalmente
distante e despida de significado pessoal, a menos que seja
deliberadamente acalentada. (SEWELL, 1978, p. 276).

De acordo com Sewell (1978), para a manutenção da qualidade do ambiente e seu controle, o comportamento precisa ser dirigido para atos específicos que devam ter precedência sobre outras possíveis ações que reflitam uma hierarquia diferente de valores. Os hábitos pessoais refletem as prioridades de valor de um indivíduo, e o tratamento com consideração para com o ambiente requer a ênfase nos valores ambientais. A informação e educação do público são indispensáveis, especialmente para desenvolver a ética ambiental, o sentimento de que todos os seres têm um direito inerente, nem que seja apenas para servir como ambiente futuro.

Conforme afirma Dias (1999), a educação ambiental é um processo por meio do qual as pessoas podem aprender como funciona o ambiente, como dependem dele, como o afetam e como promovem a sua sustentabilidade. Nesta definição, verifica-se a responsabilidade e importância dada a educação ambiental na busca pela transformação social.

Diversos trabalhos foram realizados no contexto de tal projeto, com a finalidade de avaliar as condições ambientais das propriedades rurais e a percepção ambiental de agricultores, entre os quais podem ser citados o de Arruda et al. (2001), no Assentamento Timboré em Castilho- SP, o de Poleto et al. (2004), na Microbacia Hidrográfica do Córrego do Ipê em Ilha Solteira- SP, o de Martins et al. (2005) no Assentamento Cinturão Verde de llha Solteira, o de Américo et al. (2007) em Dobrada- SP, o de Prudente Jr. (2014) em Bauru- SP e os de Tosti (2015) em Santa Fé do Sul- SP e Sakurai (2015) em Paulo de Faria- SP. 


\section{OBJETIVOS}

Caracterizar a percepção ambiental de produtores rurais do município de Castilho-SP e avaliar a importância atribuída por eles aos recursos naturais presentes nos locais de investigação.

\section{METODOLOGIA}

\section{CARACTERIZAÇÃO DA ÁREA DE ESTUDO}

Castilho localiza-se a uma latitude 2052'20" sul e a uma longitude 5129'15" oeste, na mesorregião de Araçatuba (SP). A população estimada para o ano de 2014 pelo IBGE era de 19.620 habitantes, distribuídos numa área de $1062,5 \mathrm{Km}^{2}$. Seu relevo apresenta altitude de $365 \mathrm{~m}$ e está a $642 \mathrm{~km}$ de distância da capital. (CASTILHO, 2015; INSTITUTO BRASILEIRO DE GEOGRAFIA E ESTATÍSTICAIBGE, 2015).

Possui clima seco e temperado, com temperaturas médias e inverno estável. Suas superfícies planas possuem solo arenoso de alta fertilidade, viabilizando o manejo das terras. Apresenta hidrografia de forte importância, sendo banhado pelos rios Aguapeí, Paraná e Tietê, sendo os últimos navegáveis. Sua produção agrícola é baseada na pecuária leiteira e de corte e na agricultura com cultivo de cereais, leguminosas, oleaginosas, extração vegetal e marcada ainda pelo setor sucroalcooleiro. (CASTILHO, 2015; INSTITUTO BRASILEIRO DE GEOGRAFIA E ESTATÍSTICA- IBGE, 2015).

Figura 1: Localização de Castilho no estado de São Paulo

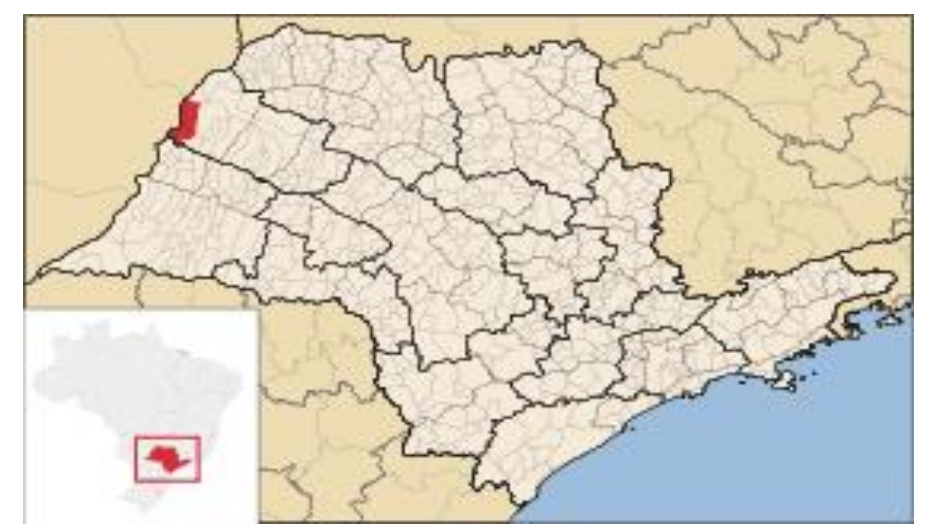

Fonte: WIKIPÉDIA, 2015. 


\section{MATERIAL E MÉTODOS}

O presente trabalho foi realizado em propriedades rurais do município de Castilho- SP, utilizando-se de um questionário baseado em Machado (1982) e Martins et al. (2005), com 26 questões contendo quadros com alternativas diversas de respostas e perguntas abertas. Os quadros de perguntas englobam a composição familiar e escolaridade; fonte de renda monetária; uso do solo; exploração vegetal e animal; tecnologias e canais de comercialização da produção; utilização de equipamentos de proteção contra defensivos agrícolas e incidência de contaminação humana; descarte de embalagens de agrotóxicos; infraestrutura existente; fontes de água existentes; lançamento de esgoto; presença de corpos d'água e matas ciliares bem como suas condições; caracterização do lixo e sua destinação; importância atribuída à água, solo, matas ciliares, florestas/matas/bosques, animais silvestres e pássaros e peixes; e por fim o tipo de assistência técnica prestada na propriedade. No presente trabalho foram enfocadas apenas as questões do questionário relacionadas à percepção ambiental dos produtores rurais quanto aos recursos naturais em suas propriedades.

Foram entrevistados 36 produtores rurais, de propriedades localizadas no Assentamento Celso Furtado e no Reassentamento Projeto Jupiá. O aspecto abordado no presente trabalho foi referente à percepção ambiental que os produtores rurais detinham sobre os itens água; florestas/bosques/matas; e animais silvestres. Posteriormente, por meio da análise de dados disposta em gráficos, procurou-se caracterizar o conhecimento geral a respeito dos recursos naturais avaliados.

\section{RESULTADOS}

Com base na análise dos relatos das ideias e percepções, relacionou-se o tipo de recurso ou componente ambiental com a respectiva importância de conservação. Tendo inicialmente a água como recurso natural avaliado, $5 \%$ dos proprietários rurais destacaram a importância do recurso para a sobrevivência e o trabalho nas propriedades, $36 \%$ como recurso essencial à vida, $42 \%$ atribuiu 
importância geral a sua conservação e 17\% à sobrevivência humana e de animais domésticos.

FIGURA 2: Importância da conservação da água

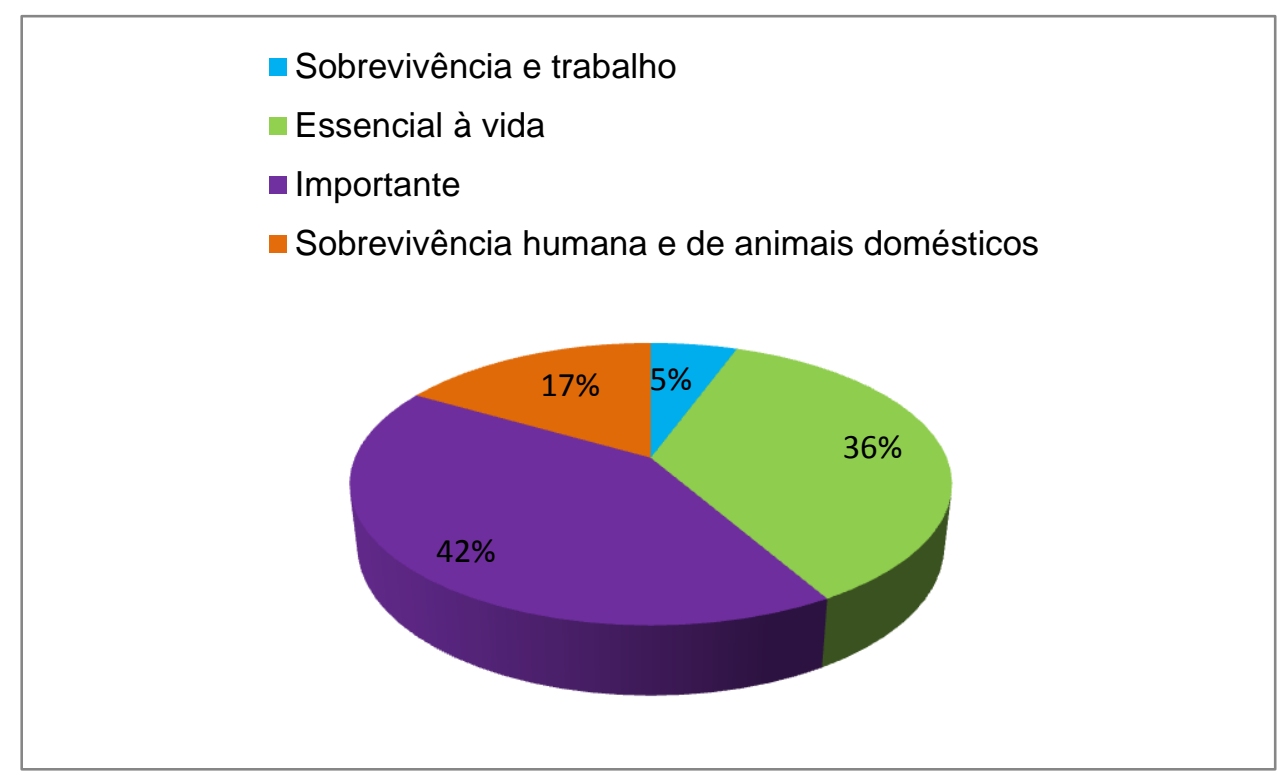

FONTE: DADOS DA PESQUISA DOS AUTORES, 2015.

Em pesquisa similar realizada em Dobrada (SP) Américo et al. (2012) relataram que $40 \%$ dos entrevistados justificaram a água como um bem essencial à vida, enquanto $33,3 \%$ mencionaram a conservação como forma de evitar a escassez. Estes dados, portanto, refletem o quão importante é a água no ambiente rural, pois determina a sobrevivência e a subsistência do produtor. Do mesmo modo, em Paulo de Faria (SP) Sakurai (2015), 100\% dos entrevistados classificaram a água como recurso natural importante.

Na região de Bauru (SP) Prudente Jr. (2014) observou que os produtores reconhecem sua necessidade em diversos ramos da produção como abastecimento, irrigação e dessedentação de animais, porém nenhum produtor deu ênfase em suas respostas quanto a sua preservação.

Em Santa Fé do Sul e região, Tosti (2015) constatou em 100\% a importância da água, exaltada como indispensável para a vida, pois tudo é dependente dela, desde a coisa mais simples quanto a mais complexa, sendo então de extrema importância para a manutenção do equilíbrio dos ecossistemas e da vida na terra, portanto, devendo ser preservada da melhor forma possível. 
Quando questionados a respeito da importância da conservação de florestas, matas e bosques, em um aspecto geral, a percepção dos produtores rurais é positiva, pois têm conhecimento de sua importância na composição do ambiente. A manutenção da umidade do ar foi abordada por $14 \%$ dos entrevistados, seguidos de $5 \%$ que sugeriram a purificação do ar e filtração de poluentes, $17 \%$ mencionaram a incidência de chuvas e ambiente de proteção aos animais silvestres, $36 \%$ apenas indicaram vagamente uma importância ou necessidade de preservação, sem mencionar motivos. Ainda assim, $5 \%$ responderam como fator de preservação de corpos d'água para dessedentação de animais domésticos, principalmente os bovinos, ao passo que $3 \%$ destacaram a relevância da fotossíntese, fonte de alimentos e sombra como aspecto para conservação de recursos vegetativos. Demais 3\% discorreram respectivamente sobre importância para seres humanos e animais e algo entendido como importância ecológica. Alguns produtores rurais não atribuíram importância à conservação de florestas e matas, totalizando 8\%; e por fim $6 \%$ deles responderam quanto à preservação e apreciação da natureza.

Figura 3: Importância da conservação de florestas/matas/bosques

Mantém a umidade

- Purificação do ar e filtração de poluentes

- Aumenta a incidência de chuvas e proteção dos animais

- Importante preservar

- Preservação de corpos d'água para animais domésticos

- Fotossíntese, alimentos e sombra

- Importante para humanos e animais

- Importância ecológica

- Sem importância ou relevância

- Preservação e apreciação da natureza

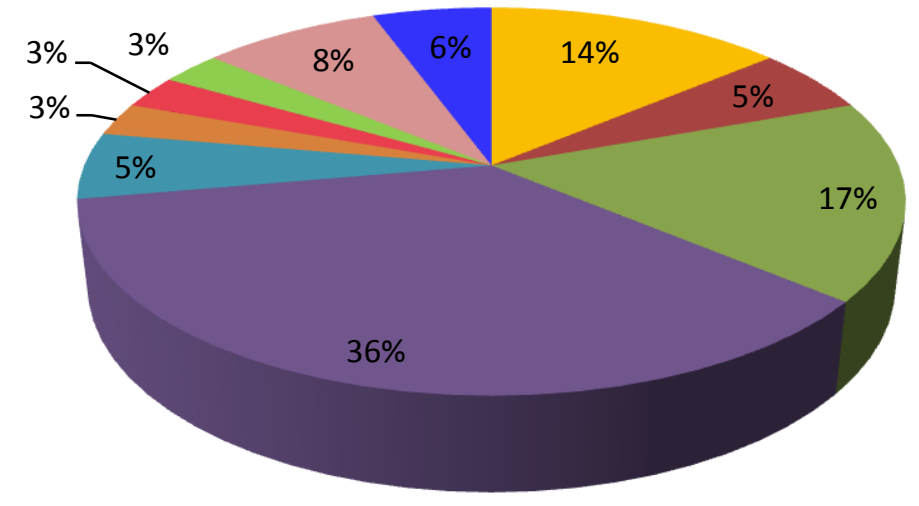

Fonte: DADOS DA PESQUISA DOS AUTORES, 2015. 
$\mathrm{Na}$ abordagem sobre conservação de matas e florestas nas propriedades em Dobrada (SP), Américo et al. (2012), destacaram que 56,6\% dos produtores rurais relacionaram sua importância como abrigo de animais silvestres, enquanto $33 \%$ referiram-se à melhora nas condições do ar e 16,7\% atentaram para o fato de que essa vegetação possa evitar mudanças climáticas.

No tema florestas, matas e bosques, Prudente Jr. (2014) observou divergência em relação à importância atribuída a cada um. Neste caso a maioria dos produtores reconhece os benefícios da conservação destes locais enquanto outros não conhecem as vantagens da manutenção destes espaços e até mesmo a apontam como prejudicial à produção agrícola, evidenciando a carência em esclarecimentos no âmbito da educação ambiental. Sobre o mesmo item, Sakurai (2015) relatou que $97,8 \%$ dos produtores de Paulo de Faria (SP) classificaram as matas ciliares e as florestas/bosques/matas como importantes, enquanto 2,2\% classificaram-nas como sendo não importantes. Em Santa Fé do Sul e região Tosti (2015) constatou em $100 \%$ dos proprietários que a conservação das matas e florestas foi considerada muito importante, pois os entrevistados afirmaram que elas são responsáveis por servir como moradia aos animais silvestres, além de contribuir com a boa qualidade do ar e impedir mudanças climáticas, como a elevação das temperaturas.

Correlacionando o grau de percepção ambiental em relação às matas, florestas e bosques, avaliou-se também a percepção acerca dos animais silvestres, como componentes destes habitats. Considerando-se a manutenção do equilíbrio ecológico e o combate à extinção, respectivos $8 \%$ dos entrevistados detinham noções de respeito e preservação da natureza. Como resultado do baixo conhecimento do funcionamento dos ecossistemas, $31 \%$ revelaram apenas que é importante preservar os animais silvestres. Respectivamente, $11 \%$ referiram-se como sendo algo benéfico ao meio ambiente e à apreciação da natureza. Ainda seguindo um pensamento de preservação e manutenção de equilíbrio ecológico, 6\% responderam a importância da conservação dos animais como função de habitar as matas. Todavia, $11 \%$ exprimiram não existir importância ou relevância em sua conservação, pelo fato de não interferirem diretamente em suas vidas; em contrapartida $14 \%$ concluíram vagamente que é importante que existam e que sejam cuidados e preservados. 
Figura 4: Importância da conservação de animais silvestres

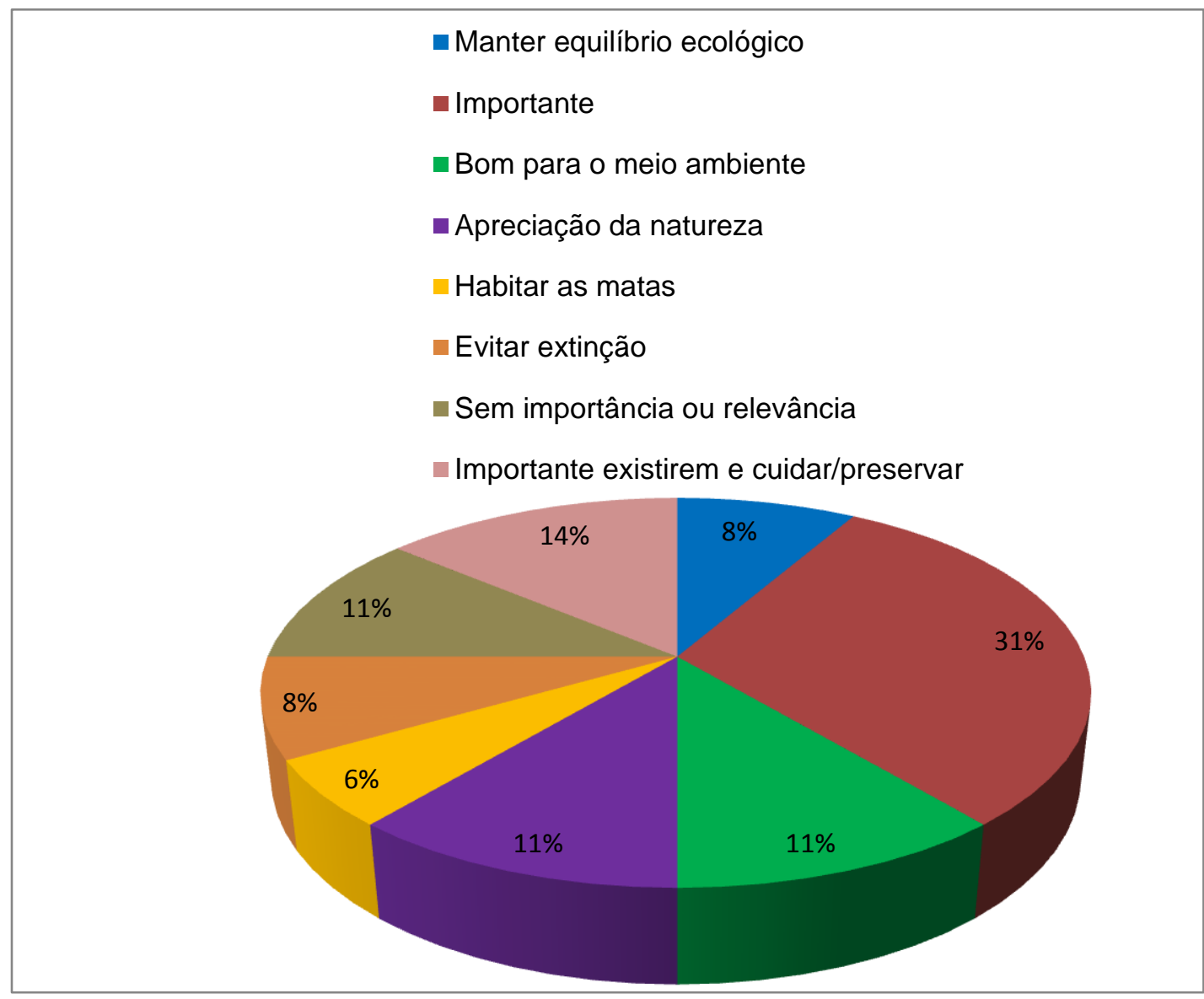

Fonte: DADOS DA PESQUISA DOS AUTORES, 2015.

No que se refere aos animais silvestres em Dobrada (SP), (Américo et al. 2012), $40 \%$ atribuíram respectivamente a: importância para impedir a extinção das espécies e manutenção do equilíbrio das cadeias alimentares. Em Bauru (SP) Prudente Jr. (2014) deparou-se com $56,67 \%$ dos produtores que defendem a preservação destes animais visando o equilíbrio ecológico na propriedade; $20 \%$ ressaltam a beleza que estes têm, defendendo também a preservação; 13,33\% indicaram como prejudicial a presença destes animais na propriedade, muitas vezes caçando-os para evitar que se alimentem das culturas, provocando um desequilíbrio ecológico local, tendo em vista que muitos consomem pragas presentes na propriedade e 10\% não atribuíram importância a animais silvestres no local.

Por sua vez, Sakurai (2015) relatou em Paulo de Faria (SP) que 91,1\% classificaram sua preservação como sendo importante, enquanto que, $8,9 \%$ 
julgaram como sendo não importante por serem perigosos e causarem prejuízos ao produtor. Em Santa Fé do Sul e região Tosti (2015) relatou que 91\% dos entrevistados disseram que a conservação de tais animais é muito importante, pois segundo eles, esses animais representam toda diversidade e beleza da natureza que deve ser mantida hoje e para as gerações futuras. Os demais, entretanto, julgaram ser pouco importante sua conservação, tendo em vista a ocorrência de prejuízos em algumas lavouras, causados quando estes animais invadem o local e se alimentam gerando assim o desagrado dos produtores.

A percepção ambiental atribuída aos animais silvestres, de forma geral, refere-se a um sentimento de dever em protegê-los, Desta forma prezam pela qualidade ambiental, preocupando-se com o risco da extinção das espécies tendo em mente um conceito ainda que rudimentar, de que a preservação é benéfica à natureza.

\section{CONCLUSÃO}

A percepção ambiental relativamente vaga em relação aos recursos naturais e seus componentes afirma a necessidade de programas voltados à educação ambiental. O conhecimento escasso acerca da conservação dos recursos naturais proveniente muitas vezes da baixa escolarização reflete em hábitos e maneiras como os produtores rurais relacionam-se com o ambiente natural onde vivem $\mathrm{e}$ trabalham. As designações para a importância da conservação ambiental e a dificuldade de argumentação e exposição de opiniões denotam que têm conhecimento da ideia de preservação ambiental, porém não detêm os conceitos e correlações para que a percepção ambiental seja tomada como ideal.

Entretanto, alguns produtores rurais mostraram-se preocupados e engajados quanto à conservação dos recursos, principalmente os vegetais, que por sua vez, acarretarão na conservação da água e de animais silvestres. Apesar de não possuírem conhecimento aprofundado sobre temas ambientais e suas vertentes, possuem o conhecimento baseado no senso comum adquirido pela prática de atividades agrícolas que requerem determinado conhecimento ambiental para que sejam favoráveis. 


\section{REFERÊNCIAS}

AMÉRICO, J. H. P.; CARVALHO, S. L.; FREITAS LIMA, E. A. C.; ARAÚJO, C. A. M. Avaliação das condições ambientais de algumas propriedades agrícolas e percepção ambiental de produtores rurais da região de Dobrada - SP. In: CONGRESSO DE ECOLOGIA DO BRASIL, 8, 2007, Caxambu. Anais... Caxambu: SEB, 2007. Disponível em: <www.seb-ecologia.org.br/viiiceb/pdf/1290.pdf.> Acesso em 24 abr. 2015.

AMÉRICO, J. H. P.; CARVALHO, S. L.; GONZAGA, M. L.; FREITAS LIMA, E. A. C.; ARAÚJO, C. A. M. Condições ambientais de propriedades agrícolas e percepção ambiental de produtores rurais do Município de Dobrada- São Paulo, Brasil. Holos Environment, Rio Claro, v. 12, n. 2, p. 241-249, 2012.

ARRUDA, S. A.; CARVALHO, S. L.; FREITAS LIMA, E. A. C.; ARAÚJO, C. A. M. Percepção ambiental de produtores rurais e das condições ambientais de seus lotes agrícolas no Assentamento Timboré em Castilho-SP. In: ENCONTRO SOBRE EDUCAÇÃO AMBIENTAL NA AGRICULTURA, 3, 2001, Campinas. Anais... Campinas: Instituto Agronômico, 2001. p.15.

CASTILHO. Prefeitura Municipal. Câmara Municipal de Castilho. História do Município. Disponível em: <http://camaracastilho.sp.gov.br>. Acesso em: 23 abr. 2015.

DIAS, G. F. Elementos para capacitação em educação ambiental. Ilhéus: Editus, 1999. 182 p.

INSTITUTO BRASILEIRO DE GEOGRAFIA E ESTATÍSTICA - IBGE. Cidades. Disponível em: <http://cidades.ibge.gov.br>. Acesso em: 23 abr. 2015.

MACHADO, A. B. M. Conservação da natureza e educação. Silvicultura em São Paulo, São Paulo, v. 16, n. 1 , p. 109-118, 1982.

MARTINS, M. Avaliação das condições sócio-econômicas-ambientais de algumas propriedades no município de llha Solteira - São Paulo. 2005. 42 f. Trabalho de Conclusão de Curso (Graduação em Agronomia) - Faculdade de Engenharia, Universidade Estadual Paulista, Ilha Solteira, 2005.

POLETO, C.; CARVALHO, S. L.; FREITAS LIMA, E. C. Problemas de degradação ambiental em uma microbacia hidrográfica situada no município de llha Solteira - SP, Brasil e sua percepção pelos proprietários rurais. Holos Environment, Rio Claro, v. 4, n. 1, p. 68-80, 2004.

PRUDENTE JÚNIOR, A. C.; AMÉRICO, J. H. P.; CARVALHO, S. L.; LIMA, E. A. C. F. Agricultura e meio ambiente: concepção ambiental de alguns produtores rurais da região de Bauru-SP. In: CONGRESSO NACIONAL DE MEIO AMBIENTE DE POÇOS DE CALDAS, 11, 2014, Poços de Caldas. Anais... Poços de Caldas: ABF, 2014. Disponível em:

<meioambientepocos.com.br/portal/anais/2014/index.php>. Acesso em: 24 abr. 2015.

SAKURAI, K. Percepção ambiental de produtores rurais e condições sócio-econômico-ambientais de propriedades agropecuárias do município de Paulo de Faria - SP. Trabalho de Conclusão de Curso. 2015. 40 f. (Graduação em Agronomia) - Faculdade de Engenharia, Universidade Estadual Paulista, Ilha Solteira, 2015.

SEWELL, G. H. Administração e controle da qualidade ambiental. São Paulo: EPU: Ed. da Universidade de São Paulo: CETESB, 1978. 295 p.

TOSTI, R. S. Percepção ambiental de produtores rurais e condições sócio-econômicoambientais de algumas propriedades agropecuárias do município de Santa Fé do Sul - SP e região. 2015. 44 f. Trabalho de Conclusão de Curso (Graduação em Agronomia) - Faculdade de Engenharia, Universidade Estadual Paulista, 2015.

WIKIPÉDIA, A ENCICLIPÉDIA LIVRE. Castilho. Disponível em: <pt.wikipedia.org/wiki/Castilho> Acesso em: 23 abr. 2015. 